\title{
COMPONENT RESOLVED IR BLEACHING STUDY OF THE BLUE LM- OSL SIGNAL OF VARIOUS QUARTZ SAMPLES
}

\author{
GEORGE S. POLYMERIS ${ }^{1}$, NAFIYE G. KIYAK ${ }^{2}$ and GEORGE KITIS ${ }^{3}$ \\ ${ }^{1}$ R.C. "ATHENA", Cultural and Educational Technology Institute, Archaeometry Laboratory, \\ Tsimiski 58, 67100-Xanthi, Greece \\ ${ }^{2}$ ISIK University, Physics Department, Faculty of Science and Arts, \\ 34980-Sile, Istanbul, Turkey \\ ${ }^{3}$ Aristotle University of Thessaloniki, Nuclear Physics Laboratory, \\ 54124-Thessaloniki, Greece
}

\begin{abstract}
The present work provides an initial component resolved analysis concerning the effect of infra-red (IR) exposure at elevated temperatures on the blue LM-OSL signal of quartz (stimulated at $470 \mathrm{~nm}$ ). The study was performed on a total of seven quartz samples, among which five originated from Turkey, one from Greece and one synthetic quartz sample. For these quartz samples, the presence of 6 or even 7 independent LM-OSL components was previously reported, after the application of a computerized decomposition analysis. IR bleaching of each one of these components is studied and compared to the respective signal reduction due to the same thermal treatment solely. It is clearly demonstrated that IR stimulation at temperatures above $50^{\circ} \mathrm{C}$ does not deplete only the fast component in most sedimentary quartz samples studied. Net depletion of fast and medium components resulting from IR exposure is sample-dependent and occurs faster as the stimulation temperature increases. Weak IR bleaching of slow components is also reported in some cases, being more effective for stimulation temperatures up to $100^{\circ} \mathrm{C}$. No depletion of either the medium or the slow components was detected for stimulation temperatures above $150^{\circ} \mathrm{C}$. Finally, IR does not stimulate any of the LM-OSL components in the case of the synthetic quartz sample.
\end{abstract}

Keywords: Infra-red (IR) stimulation, quartz, bleaching, decomposition, component - resolved analysis, LM-OSL.

\section{INTRODUCTION}

The prime motivation that led to the initial trial of optical dating (Huntley et al., 1985) was to achieve a better method of dating sediments than was possible with thermoluminescence (Aitken, 1985; 1998). Optically stimulated luminescence (OSL) from quartz is thought to arise from different traps, each having a different photoionization cross section. In dating protocols, OSL is usually measured during optical stimulation at steady stimulation power at a specific elevated temperature, resulting in a continuous wave OSL (CW-OSL) signal that decays with time but not according to a single exponential. The age is determined by using the initial part of the CW-OSL signal minus a background based on the signal level at

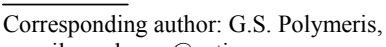

e-mail: gpolymer@ceti.gr

ISSN 1897-1695 (online), 1733-8387 (print) @ 2008 GADAM Centre, Institute of Physics, Silesian University of Technology.

All rights reserved. the end of the stimulation period. Thus, this net initial signal includes contributions from all fast, slow and medium OSL components. In some quartz samples the fast component dominates the initial CW-OSL signal. However, in others the contribution from other less lightsensitive signals can be significant (Jain et al., 2005). The presence of medium and slow components in that initial OSL signal can give rise to erroneous dose estimates while using the Single Aliquot Regenerative-dose (SAR) protocol (Murray and Wintle, 2000).

Therefore, it is desirable to use a well-separated fast OSL component in equivalent dose routines. It has been shown that the fast component can be separated from other component signals by analytical or instrumental procedures, such as curve fitting and/or linearly modulated OSL (LM-OSL) (Bulur, 1996; Jain et al., 2005). However, these procedures were proved to be extremely time-consuming and model dependent. Alternatively, Jain 
et al. (2005) recently demonstrated that in the temperature region between 120 and $190^{\circ} \mathrm{C}$ it is possible to preferentially deplete the fast component only using Infrared (IR) stimulation at $880 \mathrm{~nm}$ (FWHM $45 \mathrm{~nm}$ ). They reported that IR stimulation for $1500 \mathrm{~s}\left(115 \mathrm{~mW} \cdot \mathrm{cm}^{-2}\right)$ resulted in $10 \%$ depletion of the fast component at $160^{\circ} \mathrm{C}$ and $22 \%$ at $190^{\circ} \mathrm{C}$, while no depletion of either the medium or the slow components was detected. Based on that result, Jain et al. (2005) suggested the application of a new approach to dose estimation for quartz using a single aliquot regenerative dose protocol involving a differential measurement of the amplitude of the fast OSL component. The differential signal is calculated from two brief OSL measurements bracketing bleaching by IR photons at $160^{\circ} \mathrm{C}$. However, they have not performed deconvolution analysis; they only monitored the depletion of the LM-OSL signal at the short stimulation time region, where normally the fast component dominates.

The appearance of the first published account of possible long wavelength stimulated luminescence from quartz comes from Godfrey-Smith et al., in 1988, using combined 753 and $799 \mathrm{~nm}$ stimulation wavelengths at room temperature. At the same year, Hütt et al. (1988) presented evidence of a long wavelength resonance in some types of feldspars at near infra-red wavelengths. Later on, Short and Huntley (1992) attributed the IRSL measured at ambient temperatures using diode stimulation centred on $950 \mathrm{~nm}$ not to quartz but to feldspar micro-inclusions. In 1994, Spooner showed that IR stimulation $(\sim 860 \mathrm{~nm})$ induced extremely low depletion rates, producing measurable luminescence only at temperatures greater than $70^{\circ} \mathrm{C}$, while in a similar study Bailey (1998) reported that IR stimulation $(875 \Delta 80 \mathrm{~nm})$ yielded significant amounts of measurable luminescence from quartz only when the sample temperature was greater than $200^{\circ} \mathrm{C}$.

The present work provides an initial component resolved analysis concerning the effect of IR exposure $(880 \mathrm{~nm})$ at elevated temperatures on each one of the components of the blue LM-OSL signal of quartz (stimulated at $470 \mathrm{~nm}$ ). The study was performed on a total of 7 quartz samples, among which one is a synthetic quartz sample, five originated from Turkey and one from Greece.

\section{SAMPLES AND EXPERIMENTAL PROCEDURE}

The samples used were six sedimentary quartz samples, namely Altinkum, Atakoy, Pendik, Sile, Patara and Chalkidiki (laboratory references ALT, ATK, PDK, SLE, PTR, and CHL respectively), along with an artificial quartz sample provided by MERCK Company (laboratory reference MERC). Samples ALT, ATK, PDK and SLE were recovered from the coastal area around Istanbul and described in some detail previously by Kiyak and Canel (2006). The PTR sample is a proposed tsunamilaid deposit from the ancient city of Patara, located on Antalya's Mediterranean coast in Turkey. The CHL sample, collected from the coast of Chalkidiki region in Northern Greece, was earlier studied by Polymeris et al., 2006a. Quartz purity of samples as well as the absence of any feldspar inclusions was verified by preliminary XRD measurements.

All measurements were performed using an automated Risø TL/OSL reader (model TL/OSL-DA-15, Bøtter-Jensen et al., 2000), equipped with an internal ${ }^{90} \mathrm{Sr} /{ }^{90} \mathrm{Y}$ beta source $\left(\sim 0.1\right.$ Gy s $\left.{ }^{-1}\right)$. Blue light emitting diodes (LEDs) (470 nm, FWHM $40 \mathrm{~nm}, \sim 40 \mathrm{~mW} \mathrm{~cm}^{-2}$ ) and IR LEDs ( $880 \mathrm{~nm}$, FWHM $80 \mathrm{~nm}, \sim 135 \mathrm{~mW} \mathrm{~cm}^{-2}$ ) were used for stimulation. Luminescence signal detection was made using an EMI 9635QA photomultiplier tube, fitted with Hoya U-340 filters of $7.5 \mathrm{~mm}$ total thickness.

Two experimental protocols were used in the study (as presented in Table 1) in order to compare the behaviour of the samples under different experimental conditions. Our protocol is a slight variation of the protocol used by Jain et al. (2003), in which they used LM-IR light intensity from 0 to $230 \mathrm{~mW} \mathrm{~cm}^{-2}$.

As presented in Table 1 one aliquot of each sample was pre-sensitised to $650^{\circ} \mathrm{C}$ and immediately afterwards irradiated with 10 Gy beta dose; it was preheated to $200^{\circ} \mathrm{C}$ and then stimulated by LM-IR light from 0 to $130 \mathrm{~mW} \mathrm{~cm}^{-2}$ at various temperatures $\mathrm{T}^{\circ} \mathrm{C}(25,50,100$, $25,150,200$ and $25^{\circ} \mathrm{C}$ ) for $5 \mathrm{ks}$. A measurement cycle at $25^{\circ} \mathrm{C}$ was repeated after every two cycles to monitor sensitivity changes. A blue stimulated LM-OSL at $125^{\circ} \mathrm{C}$ was recorded after LM-IR measurements. In the second protocol, similar measurement sequence was used (Table 1), for a second aliquot that was held at the same temperatures $\mathrm{T}{ }^{\circ} \mathrm{C}\left(25,50,100,25,150,200\right.$ and $\left.25^{\circ} \mathrm{C}\right)$ for $5 \mathrm{ks}$ without IR stimulation during the $4^{\text {th }}$ step; this was to ascertain the charge depletion resulting from holding the sample at elevated temperature for $5 \mathrm{ks}$ during the $4^{\text {th }}$ step of protocol 1 . One aliquot of each sample was used for each protocol.

\section{METHOD OF ANALYSIS}

All LM-OSL curves obtained were analyzed by a computerized decomposition procedure assuming firstorder kinetics for all possible components (Jain et al., 2003; Kiyak et al., 2007). The first-order kinetics assumption is based on a direct extrapolation from the experience gained from the thermoluminescence (TL) studies of the glow-curve of quartz, where no higher order kinetics glow-peaks exist. The first-order kinetics equation describing a LM-OSL peak proposed by Bulur (1996) was used. However, the original Bulur's Eq. (1), was transformed, so that instead of the parameters $n_{0}$ and $\sigma$, to contain the parameters $I_{m}$ and $t_{m}$ directly obtained from the experimental curves. The transformed form given by Polymeris et al. (2006b) is:

Table 1. Protocols used in the study.

\begin{tabular}{|c|c|}
\hline Protocol 1 (IR Stimulation) & Protocol 2 (Thermal treatment) \\
\hline 1. Pre-sensitised to $650^{\circ} \mathrm{C}$ & 1. Pre-sensitised to $650^{\circ} \mathrm{C}$ \\
\hline 2. Irradiation with $10 \mathrm{~Gy}$ & 2. Irradiation with $10 \mathrm{~Gy}$ \\
\hline 3. $\mathrm{PH}$ to $200^{\circ} \mathrm{C}$ for $10 \mathrm{~s}$ & 3. $\mathrm{PH}$ to $200^{\circ} \mathrm{C}$ for $10 \mathrm{~s}$ \\
\hline $\begin{array}{l}\text { 4. LM-IR stimulation at } \mathrm{T}^{\circ} \mathrm{C} \\
\text { for } 5 \mathrm{ks}\end{array}$ & 4. $\mathrm{PH}$ at $\mathrm{T}^{\circ} \mathrm{C}$ for $\mathbf{5} \mathrm{ks}$ \\
\hline $\begin{array}{l}\text { 5. Blue stimulated LM-OSL at } \\
125^{\circ} \mathrm{C} \text { for } 10 \mathrm{ks}\end{array}$ & $\begin{array}{l}\text { 5. Blue stimulated LM-OSL at } \\
125^{\circ} \mathrm{C} \text { for } 10 \mathrm{ks}\end{array}$ \\
\hline
\end{tabular}


$I(t)=1.6488 \frac{I_{m}}{t_{m}} t \cdot \exp \left(-\frac{t^{2}}{2 t_{m}^{2}}\right)$

where:

$I_{m}$ and $t_{m}$, are the values of OSL intensity and time at the maximum of the LM-OSL peak, respectively, and $t$ the stimulation time. Eq. (3.1) was used for the decomposition of all experimental data. The curve fitting was performed using the MINUIT program (James and Roos, 1977), whereas the goodness of fit was tested by the Figure Of Merit (FOM) of Balian and Eddy (1977), given by:

$F O M=\sum_{i} \frac{\left|Y_{\text {Exper }}-Y_{F i t}\right|}{A}$

where:

$Y_{\text {Exper }}$ is the experimental glow-curve, $Y_{F i t}$ is the fitted glow-curve and $A$ is the area of the fitted glow-curve. The background was simulated by an equation of the form:

$b g=z_{d}\left(C+\frac{t}{P}\right)$

where:

$z_{d}$ is the zero dose OSL signal after blue stimulation and $P$ the total stimulation time. The parameter $z_{d}$ is evaluated experimentally, by measuring the background OSL signal at non-irradiated samples. $C$ is a constant, very close to unity. The increase of the background with time is clearly demonstrated by the pioneer LM-OSL paper by Bulur et al., (2002). Furthermore, the formula 3.3 is the most common formula for the background, since it was successfully applied to all previous studies dealing with decomposition of LM-OSL curves resulting from quartz.

\section{RESULTS AND DISCUSSION}

\section{Linearly modulated blue and IR stimulated lumines- cence curves}

For most of these quartz samples, the presence of 6 or even 7 independent Blue LM-OSL components was previously reported (Kitis et al., 2007; Kiyak et al., 2007; 2008). LM-OSL curve shapes and decomposition analysis examples for samples ALT, ATK, PDK and SLE were previously reported by Kiyak et al. (2007) using six individual LM-OSL components, while for sample CHL by Kiyak et al., (2008) using seven individual LM-OSL components. Therefore blue LM-OSL curve shapes analyzed and resolved into their individual components are presented in Figs. 1 and $\mathbf{2}$ for the quartz samples PTR and MERC respectively. Six LM-OSL components were used for the decomposition of the former, while seven for the latter, which provides signal with relatively low intensity, due to the fact that it is a quartz sample of synthetic origin.

The values of the $t_{m}$ used for the decomposition were chosen in the region reported previously by these preceding authors, after an extra correction according to the formula: $\frac{t_{m 1}}{t_{m 2}}=\sqrt{\frac{T_{1}}{T_{2}}}$

where:

$T_{1}$ and $T_{2}$ are the different stimulation times. This correction is inevitable, since the stimulation time in the case of the present study is $10 \mathrm{ks}$, while in the cases of previously reported papers the stimulation time was much less. Therefore, each peak maximum position shifts to lower stimulation times as the stimulation duration increases. The FOM values were of the order of $2 \%$ (in cases of LM-OSL glow curves of low intensity) and better.

Fig. 3 presents IR LM-OSL curves for the PTR and ALT quartz samples. For each one of these, 4 curves are presented, namely IR LM-OSL signal after stimulation at $50,100,150$ and $200^{\circ} \mathrm{C}$. The LM-IR glow curves for the ALT sample are presented as typical for all other quartz samples of Turkish origin. The signal is of extremely low intensity, especially in the case of low stimulation temperatures up to $100^{\circ} \mathrm{C}$. For stimulation temperatures be-

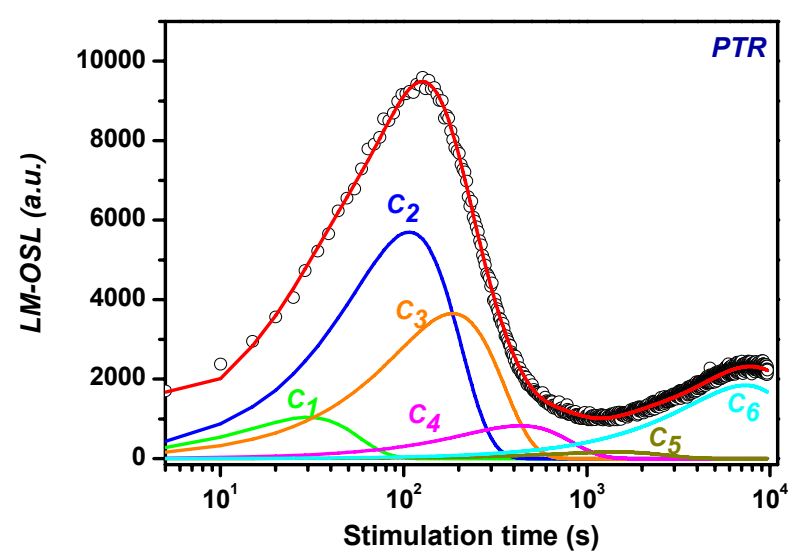

Fig. 1. LM-OSL curve of Patara quartz sample received at $125^{\circ} \mathrm{C}$ (lab code PTR), deconvoluted into 6 individual components. Dose $10 \mathrm{~Gy}$, $\mathrm{PH}$ to $200^{\circ} \mathrm{C}$ for $10 \mathrm{~s}$. The time axis is given in log scale in order to observe, clearly, all components at short stimulation times.

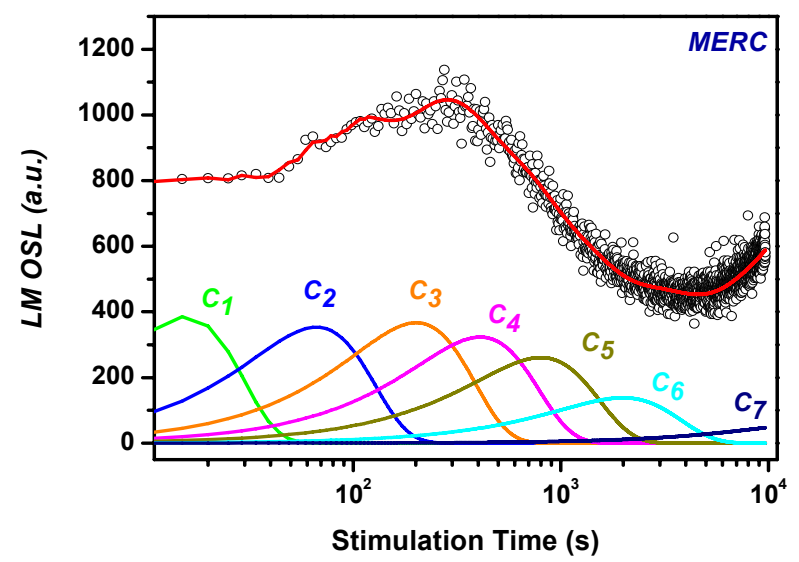

Fig. 2. Component resolution of the LM-OSL curve of the Merck synthetic quartz sample received at $125^{\circ} \mathrm{C}$ (lab code MERC). Six individual components were used for the deconvolution. Dose $10 \mathrm{~Gy}, \mathrm{PH}$ to $200^{\circ} \mathrm{C}$ for $10 \mathrm{~s}$. The time axis is given in log scale in order to observe, clearly, all components at short stimulation times. 


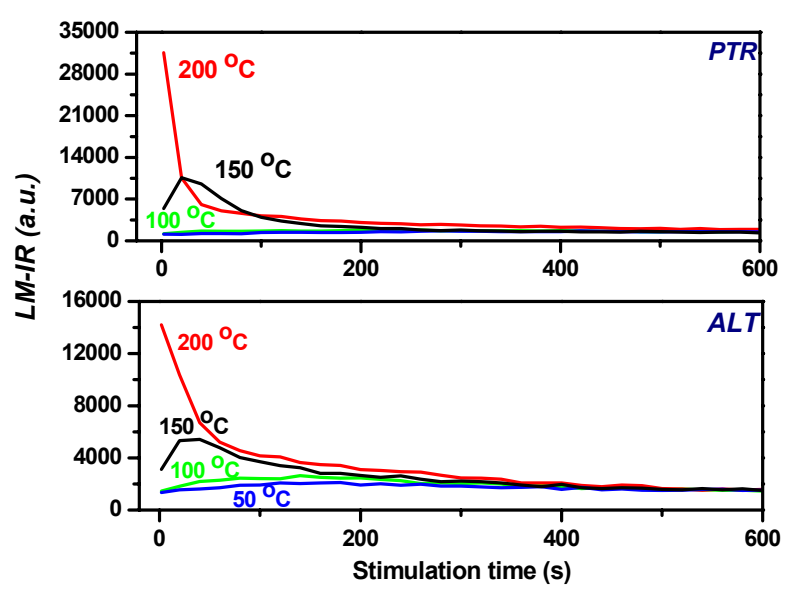

Fig. 3. IR-LM glow curves for two different quartz samples; PTR (upper figure) and ALT (lower figure). IR LM curves for four different stimulation temperatures are presented for each sample. Dose $10 \mathrm{~Gy}, \mathrm{PH}$ to $200^{\circ} \mathrm{C}$ for $10 \mathrm{~s}$.

tween 50 and $150^{\circ} \mathrm{C}$, the signal forms a wide peak for short stimulation times; the maximum position is shifted towards lower stimulation times as the stimulation temperature is increased. Despite the fact that stimulating at $200^{\circ} \mathrm{C}$ provides a signal yielding much better statistics, its shape is dramatically changed, i.e. there is not a peak any more and the signal is monotonically depleted with time as in the case of Continuous Wave OSL (CW-OSL).
Signal-to-noise ratio is still very low, especially for long stimulation times. Therefore, the IR LM-OSL signals were not decomposed and analyzed into their individual components.

One notable exception is observed for the PTR quartz sample. For stimulation temperatures up to $100^{\circ} \mathrm{C}$, the LM IR glow curves are totally flat. However, for higher stimulation temperatures, the LM IR signal is of great intensity, also forming a peak for short stimulation times at $150^{\circ} \mathrm{C}$, while at $200^{\circ} \mathrm{C}$ not only is very intense, but it is also monotonically depleted also, as in the case of Continuous Wave OSL (CW-OSL).

\section{Component Resolved IR bleaching}

IR bleaching was carried out to investigate the depletion rates of each one of the blue LM-OSL components of quartz as a function of the stimulation temperature. The high temperature annealing during the stimulation causes significant depletion of the blue LM-OSL signal. In order to monitor the depletion due to purely IR stimulation, the second experimental protocol was applied, namely the aliquots were held at the same elevated temperatures without IR stimulation in order to study the loss of signal due to thermal decay alone.

For most of the quartz samples studied, IR stimulation at elevated temperatures bleaches the entire blue LMOSL curve. This feature is illustrated in Fig. 4, where for each one of the samples studied, blue LM-OSL curves are
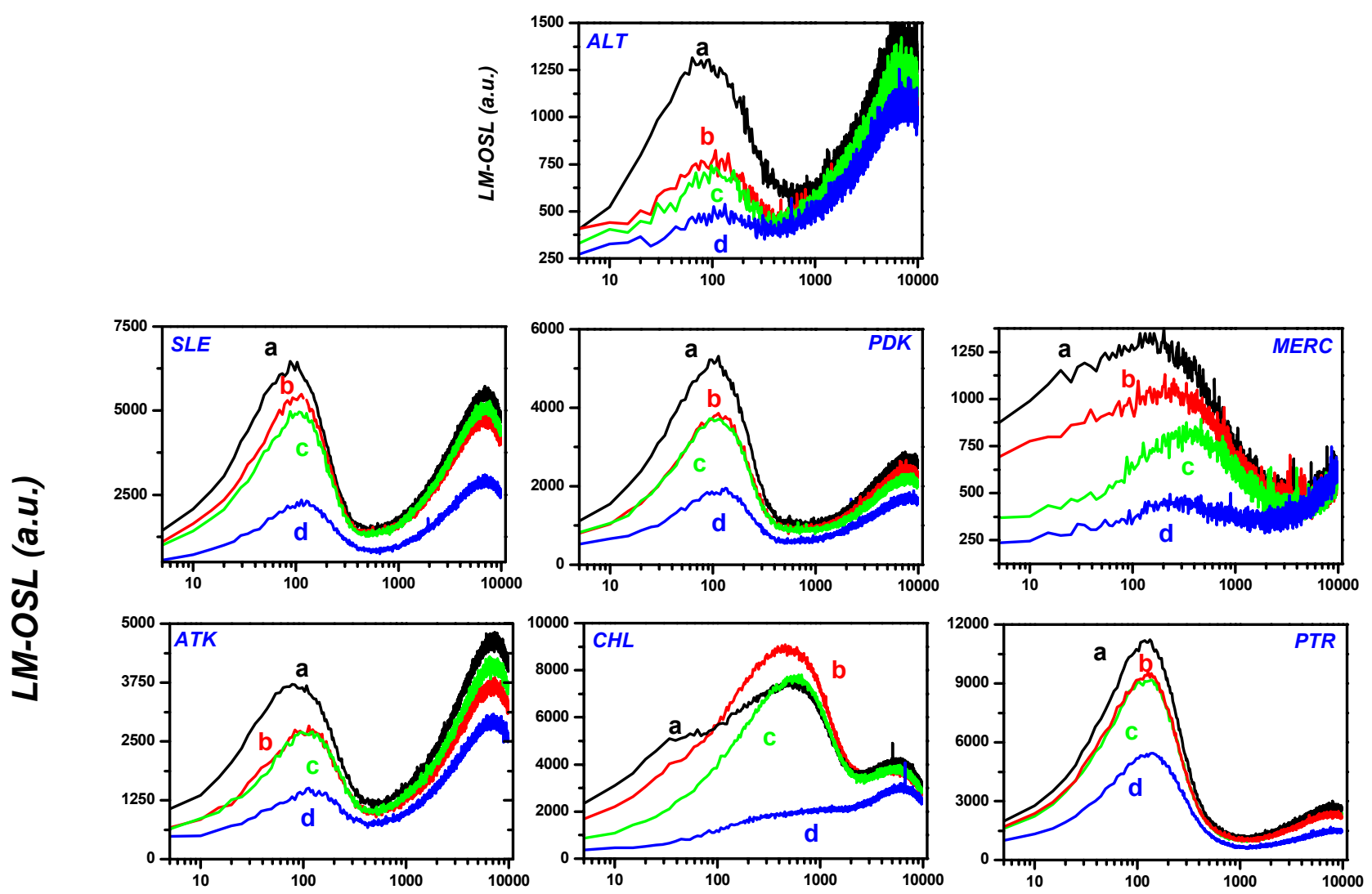

\section{Stimulation time (s)}

Fig. 4. Blue LM-OSL curves for all quartz samples studied, under four different conditions of IR stimulation; without IR exposure (curve a), after IR stimulation at $25^{\circ} \mathrm{C}$ (curve b), at $100^{\circ} \mathrm{C}$ (curve c), and at $200^{\circ} \mathrm{C}$ (curve d). The time axis is given in log scale. 
presented under four different conditions of IR stimulation; without IR exposure (curve a), after IR stimulation at $25^{\circ} \mathrm{C}$ (curve b), at $100^{\circ} \mathrm{C}$ (curve c), and at $200^{\circ} \mathrm{C}$ (curve d). It is interesting to point out that curves in Fig. 4 are not corrected for sensitivity changes, since the measurement cycles at $25^{\circ} \mathrm{C}$, repeated after every two cycles, indicated sensitivity changes of the order of $5 \%$ per two cycles or even less. Depletion resulting only from IR stimulation is recorded for the fast components, even at the lowest stimulation temperature, implying that quartz's insensitivity to IR stimulation at room temperature firstly suggested by Short and Huntley (1992) may be sample dependent. This result is also contradictory to the conclusions suggested by Jain et al. (2003, 2005). These authors reported that only the quartz fast component appears to be optically stimulated by IR at temperatures between 120 and $190^{\circ} \mathrm{C}$ and that no depletion of either the medium or fast component was detected at the same temperature region. These results were consistent for the quartz samples studied of Indian, Danish and Australian origin. However, they have not performed deconvolution analysis; they only monitored the depletion of the LM-OSL signal at the short stimulation time region, where normally the fast component dominates.

All OSL components $C_{i}$, appear under the same names for all the samples, due to the strong correlation between individual components from different quartz samples. This correlation is strongly supported by the values of trap parameters determined by the decomposition procedure. Those parameters are the $\mathrm{t}$ maximum position $\mathrm{t}_{\max }$ as well as the photo - ionization cross section $\sigma$. From Figs. 1 and $\mathbf{2}$ it becomes prominent that in all quartz samples studied each component $C_{i}$ appears at almost the same $t_{\max }$ position. This is the first and most interesting correlation between several components from different samples. Furthermore, all components at the same $t_{\max }$ position yield similar photo-ionization cross section values. Both $\mathrm{t}_{\max }$ (for $3600 \mathrm{~s}$ of stimulation) and $\sigma$ values were previously reported for samples ATK, ALT, PDK and SLE by Kiyak et al. (2007). The aforementioned correlations between several components from different quartz samples are strongly supported by those numbers. The $\sigma$ values for the other quartz (CHL, PTR and MERC) samples are adequately similar to further support this correlation. Furthermore, the photoionization cross section values are reproducible during the bleaching process to within $\pm 15 \%$ for the first three components to less than $25 \%$ for the others, providing thus the best test of the first order model assumption correctness.

The individual behaviours of components $C_{1}, C_{2}$ and $C_{3}$ are similar. Furthermore, the values of the $t_{m}$ for those three components are very close. Therefore, these three components are treated together as a sum for all quartz samples under study, except the MERC quartz sample, where the components $C_{1}, C_{2}, C_{3}$ and $C_{4}$ are treated together for the same reasons. Depletion of components $C_{l}$, $C_{2}$ and $C_{3}$ is presented in the lower part of Fig. 5, while depletion of components $C_{1}, C_{2}, C_{3}$ and $C_{4}$ are presented in the lower part of Fig. 6 for the MERC quartz sample. The high temperature annealing (curves (a) of Fig. 5) causes moderate depletion of the blue LM-OSL signal, except the case of the PTR quartz sample, where the signal is sensitized. IR stimulation at elevated temperatures (curves b of Fig. 5) further depletes the blue LMOSL signal, not only in the temperature region between 150 and $200^{\circ} \mathrm{C}$ as it was previously reported and is true for the samples SLE and CHL, but even for lower stimulation temperatures. This is exactly the case for samples ALT, ATK, PDK and PTR, where the IR stimulation is effective even at the low stimulation temperature of $50^{\circ} \mathrm{C}$. For the MERC quartz sample, the strong depletion of the LM-OSL is attributed only to the thermal treatment, since IR stimulation does not cause further depletion to components 1 to 4 .

Medium components $C_{4}$ and $C_{5}$ are also treated together for the six sedimentary quartz samples for the same reasons. The effects of both annealing as well as IR stimulation at high temperatures are presented as curves (a) and (b) respectively in the middle panels of Fig. 5 . While annealing in the temperature region $50-200^{\circ} \mathrm{C}$ causes significant depletion to these components in all quartz samples, the effect of the IR stimulation is sampledependent, causing strong depletion in the case of the ATK sample, moderate one in the case of the ALT sample and small depletion for samples PTR and SLE. Finally, for samples MERC, CHL and PDK the IR stimulation does not deplete further the blue LM-OSL signal of the medium components. Furthermore, bleaching of the medium components is stronger in the low stimulation temperature region, namely for temperatures up to $100^{\circ} \mathrm{C}$.

Explanation of the similar behaviour of the separate OSL components when the first order kinetics model is assumed becomes a difficult task. This similar behaviour of some separate OSL components could be simply attributed to the fact that first order model is not a good approximation and the signal of some components originates probably from one trap. However, this would have not been the case for sequential LM-OSL components. Nevertheless, this assumption regarding the weakness of the first order kinetics model should be presented openly, despite the fact that very good reproducibility of the photo-ionization cross section values during the IR bleaching process is a clear experimental result that strongly supports the first order model assumption correctness. Assuming the latter, similar behaviour of LMOSL components could be possibly attributed to the use of the same recombination centre.

However, the most interesting result is the weak IR bleaching of slow components, whose depletion is presented in the upper panels of Fig. 5. It is clearly demonstrated that annealing at high temperatures does not cause significant loss of the signal in all quartz samples, unless the temperature is $200^{\circ} \mathrm{C}$. Furthermore, it is also prominent that in some quartz samples, such as ATK, ALT, PDK and PTR, weak IR bleaching of slow components takes place; while for the three other samples (SLE, PTR and CHL) IR does not stimulate any of the slow LM-OSL components. This slow LM-OSL component IR bleaching is more effective when the stimulation occurs at the temperature region between 100 and $150^{\circ} \mathrm{C}$. Finally, as in the case of the medium components, no depletion of the slow components was detected for stimulation temperatures above $150^{\circ} \mathrm{C}$. 

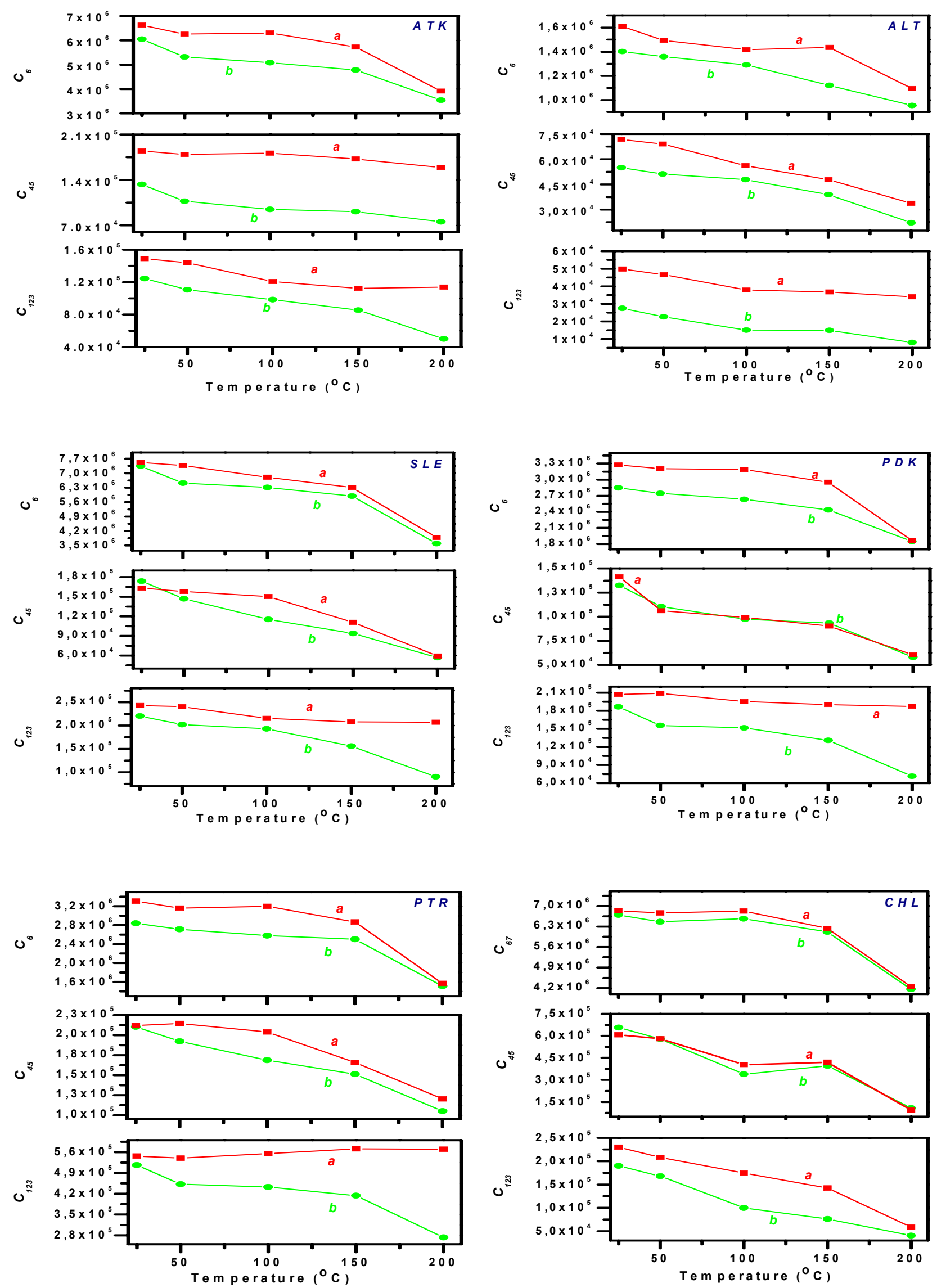

Fig. 5. Component resolved depletion curves of the blue LM-OSL signal for all sedimentary quartz samples studied, after elevated temperature annealing (curves a) and IR stimulation at elevated temperatures (curves b) as a function of the temperature applied; sum of the fast components $C_{1}, C_{2}$ and $C_{3}$ (lower figures), sum of medium components $C_{4}$ and $C_{5}$ (middle figures) and slow component $C_{6}$ (and $C_{7}$ in case of $C H L$ sample, upper figures).. 

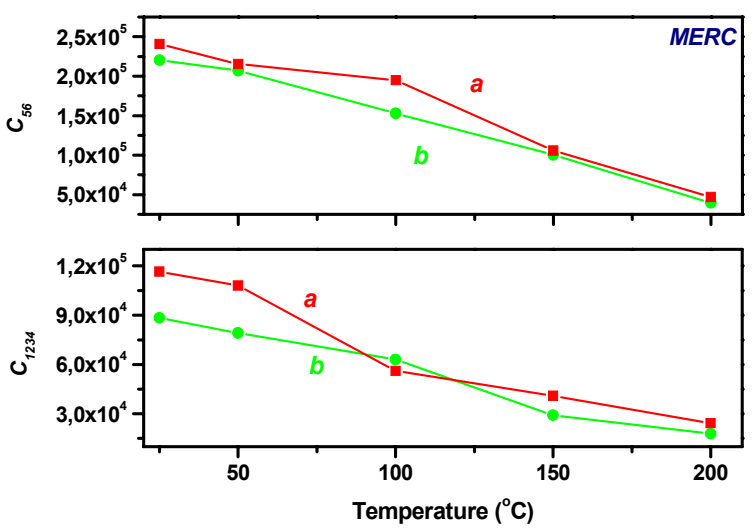

Fig. 6. Component resolved depletion curves of the blue LM-OSL signal for the MERC synthetic quartz sample, after elevated temperature annealing (curves a) and IR stimulation at elevated temperatures (curves b) as a function of the temperature applied; sum of the fast components $C_{1}, C_{2}, C_{3}$ and $C_{4}$ (lower figure), sum of medium components $C_{5}$ and $C_{6}$ (upper figure). IR does not stimulate any of the LM-OSL components.

\section{CONCLUSIONS}

IR bleaching of the blue LM-OSL components of quartz is studied and compared to the respective signal reduction due to the same thermal treatment solely for seven different quartz samples. IR LM-OSL curves are also presented. It is clearly demonstrated that IR stimulation at temperatures above $50^{\circ} \mathrm{C}$ does not deplete only the fast component in most sedimentary quartz samples studied. Net depletion of fast and medium components resulting from IR exposure is sample-dependent and occurs faster as the stimulation temperature gets higher. Weak IR bleaching of slow components is also reported in some cases, being more effective for stimulation temperatures in the region between 100 and $150^{\circ} \mathrm{C}$. No depletion of either the medium or the slow components was detected for stimulation temperatures above $150^{\circ} \mathrm{C}$. Finally, IR does not stimulate any of the LM-OSL components in the case of the synthetic quartz sample.

\section{ACKNOWLEDGEMENTS}

The present work was partially funded by the Greek General Secretariat of Research and Technology and the E.C., under the programme "Excellence in Research Institutes GSRT ( $2^{\text {nd }}$ round)", sub-programme "Support for Research Activities in C.E.T.I.”.

\section{REFERENCES}

Aitken MJ, 1985. Thermoluminescence Dating. London, Academic Press: $359 \mathrm{pp}$.

Aitken MJ, 1998. An introduction to optical dating. Oxford, Oxford
University Press: 267pp.

Bailey RM, 1998. Depletion of the quartz OSL signal using low photon energy stimulation. Ancient TL 16(2): 33-36.

Balian HG and Eddy NW, 1977. Figure - Of - Merit (FOM). An improved criterion over the normalized $\mathrm{Chi}$ - squared test for assessing goodness - of - fit of gamma - ray spectral peaks. Nuclear Instruments and Methods 145(2): 389-395, DOI 10.1016/0029554X(77)90437-2.

Bøtter-Jensen L, Bulur E, Duller GAT and Murray AS, 2000. Advances in luminescence instrument systems. Radiation Measurements 32: 523-528, DOI 10.1016/S1350-4487(00)00039-1.

Bulur E, 1996. An alternative technique for optically stimulated luminescence (OSL) experiment. Radiation Measurements 26(5): 701709, DOI 10.1016/S1350-4487(97)82884-3.

Bulur E, Duller GAT, Solongo S, Bøtter-Jensen L and Murray AS, 2002. LM-OSL from single grains of quartz: a preliminary study. Radiation Measurements 35(1): 79-85, DOI 10.1016/S13504487(01)00256-6.

Godfrey-Smith DI, Huntley DJ and Chen WH, 1988. Optical dating studies of quartz and feldspar sediment extracts. Quaternary Science Reviews 7(3-4): 373-380, DOI 10.1016/02773791(88)90032-7.

Huntley DJ, Godfrey-Smith DI and Thewalt MLW, 1985. Optical dating of sediments. Nature 313: 105-107, DOI 10.1038/313105a0.

Hütt G, Jaek I and Tchonla J, 1988. Optical Dating: K-feldspars optical response stimulation spectra. Quaternary Science Reviews 7(3-4): 381-386, DOI 10.1016/0277-3791(88)90033-9.

Jain M, Murray AS, Bøtter-Jensen L and Wintle AG, 2005. A singlealiquot regenerative-dose method based on IR $(1.49 \mathrm{eV})$ bleaching of the fast OSL component in quartz. Radiation Measurements 39(3): 309-318, DOI 10.1016/j.radmeas.2004.05.004.

Jain M, Murray AS and Bøtter-Jensen L, 2003. Characterisation of blue light stimulated luminescence components in different quartz samples: implications for dose measurement. Radiation Measurements 37(4-5): 441-449, DOI 1 0.1016/S1350-4487(03)00052-0.

James F and Roos M, 1977. MINUIT, CERN program library entry D506. http://consult.cern.ch/writeups/minuit.

Kitis G, Polymeris GS and Kiyak NG, 2007. Component-resolved thermal stability and recuperation study of the LM-OSL curves of four sedimentary quartz samples. Radiation Measurements 42(8): 1273-1279, DOI 10.1016/j.radmeas.2007.05.050.

Kiyak NG and Canel T, 2006. Equivalent dose in quartz from young samples using the SAR protocol and the effect of preheat temperature. Radiation Measurements 41(7-8): 917-922, DOI 10.1016/j.radmeas.2006.04.006.

Kiyak NG, Polymeris GS and Kitis G, 2007. Component resolved OSL dose response and sensitization of various sedimentary quartz samples. Radiation Measurements 42(2): 144-155, DOI 10.1016/j.radmeas.2007.02.052.

Kiyak NG, Polymeris GS and Kitis G, 2008. LM-OSL thermal activation curves of quartz: Relevance to the thermal activation of the $110^{\circ} \mathrm{C}$ TL glow peak. Radiation Measurements 43(2-6): 263-268, DOI 10.1016/j.radmeas.2007.12.039.

Murray AS and Wintle AG, 2000. Luminescence dating of quartz using an improved single-aliquot regenerative-dose protocol. Radiation Measurements 32: 57-73, DOI 10.1016/S1350-4487(99)00253-X.

Polymeris G, Kitis G and Pagonis V, 2006a. The effects of annealing and irradiation on the sensitivity and superlinearity properties of the $110^{\circ} \mathrm{C}$ thermoluminescence peak of quartz. Radiation Measurements 41(5): 554-564, DOI 10.1016/j.radmeas.2006.03.006.

Polymeris GS, Tsirliganis NC, Loukou Z and Kitis G, 2006b. A comparative study of the anomalous fading effects of TL and OSL signals of Durango apatite. Physica Status Solidi A 203(3): 578-590, DOI 10.1002/pssa.200521347.

Short MA and Huntley DJ, 1992. Infra-red stimulation of quartz. Ancient TL 10: 19-21.

Spooner NA, 1994. On the optical dating signal from quartz. Radiation Measurements 23(2-3): $\quad 593-600, \quad$ DOI $\quad 10.1016 / 1350-$ 4487(94)90105-8. 